\title{
Subventricular Zone Radiation Dose and Outcome for Glioblastoma Treated Between 2006 and 2012
}

Sonja C. Murchison ${ }^{1}$, Bradley Wiksyk ${ }^{2}$, Stacey Gossman ${ }^{1}$, Brigit Jensen ${ }^{1}$, Dorothy Sayers ${ }^{1}$, Mary Lesperance $^{3}$, Pauline T. Truong ${ }^{1}$, Abraham Alexander ${ }^{1}$

1. Radiation Oncology, British Columbia Cancer Agency - Vancouver Island Centre, Victoria, CAN 2. Internal Medicine, University of British Columbia, Vancouver, CAN 3. Oncology, University of Victoria, Victoria, CAN

Corresponding author: Sonja C. Murchison, sonja.murchison@bccancer.bc.ca

\section{Abstract \\ Objective}

Stem cells residing in the subventricular zone (SVZ) may be related to recurrence, potentially affecting outcome in glioblastoma (GBM). This study investigated the relationship of SVZ radiation dose and survival in a large cohort treated with surgery and chemoradiotherapy (CRT).

\section{Methods}

Patients with GBM treated between 2006 and $2012(n=370)$ were identified. SVZs were contoured from planning computed tomography (CT) with magnetic resonance imaging (MRI) registration where available. Dose was extracted from dose volume histograms. Kaplan-Meier (KM) progression-free survival (PFS) and overall survival (OS) estimates were compared with log-rank tests for SVZ doses. Multivariate analysis (MVA) identified clinical and treatment-related factors significantly associated with outcome.

\section{Results}

Median follow-up was 16.4 months, $48.1 \%$ underwent gross total resection (GTR), 37.5\% subtotal resection, and $14.4 \%$ biopsy without resection. Median PFS was 8.9 months (95\% CI: 8.3-9.8 months), and OS was 16.5 months (95\% CI: $15.2-17.6$ months). PFS was significantly lower for older age ( $>50$ years, $\mathrm{P}=0.045$ ), poor Karnofsky performance status (KPS, $\mathrm{P}=0.049)$, multifocality $(\mathrm{P}<0.001)$, and incomplete adjuvant chemotherapy ( $\mathrm{P}<0.001)$. Worse OS was associated with poor KPS $(\mathrm{P}=0.001)$, biopsy only $(\mathrm{P}=0.003)$, multifocality $(\mathrm{P}=0.009)$, and failure to complete adjuvant chemotherapy $(\mathrm{P}<0.001)$. SVZ dose was not associated with outcome for any of the dose levels assessed. On MVA, multifocality was associated with worse PFS $(\mathrm{P}<0.01)$. Poor performance status and biopsy only were associated with worse OS (both $\mathrm{P}<$ $0.01)$.

\section{Conclusion}

Received 11/05/2018

Review began 11/14/2018 Review ended 11/15/2018 Published 11/21/2018

\section{() Copyright 2018}

Murchison et al. This is an open access article distributed under the terms of the Creative Commons Attribution License CC-BY 3.0., which permits unrestricted use, distribution, and reproduction in any medium, provided the original author and source are credited.
In this analysis of a large cohort of GBM treated with surgery and CRT, increased SVZ dose was not associated with improved survival.

Categories: Radiation Oncology, Neurosurgery

Keywords: glioblastoma, subventricular zone, radiotherapy, stem cells

\section{Introduction}

Standard treatment for glioblastoma (GBM) in patients younger than 65-70 years involves maximal surgical resection plus radical long-course chemoradiotherapy, followed by adjuvant chemotherapy with temozolomide [1]. Despite aggressive multimodality therapy, prognosis remains poor, with a median overall survival of 14.6 months, and two-year overall survival of $27 \%$.

Tumor-like stem cells (TLSC) exhibit properties that help maintain and promote tumor growth [2,3]. TLSC have been isolated and extensively studied in GBM [2-5]. Research suggests they may contribute to negative outcomes associated with this disease. In both cultured cells and mice models, neural stem cells (NSC) and TLSC both express CD133, which is correlated with greater radioresistance, repopulation, and DNA damage checkpoint response [6]. Disrupted K-ras signaling, a biologic regulator of NSC, has been shown to induce gliomatosis [7]. Mutations in epidermal growth factor receptor (EGFR) have also been encountered in glioma, and in NSC, confer a proliferative advantage and enhanced tumor cell survival [8]. One wellcharacterized reservoir of NSC in humans is the subventricular zone (SVZ) [9-12]. In some studies, tumor proximity or involvement of the SVZ has been related to poorer prognosis [13-15].

In recent years, there has been speculation as to whether irradiation of NSCs in the SVZ may improve outcome. Unfortunately, there is limited data on the impact of dose to the SVZ, which consists of mostly 
small, retrospective studies with conflicting results [16-26]. Some of these studies suggest that higher dose to the SVZ is associated with better outcome, raising the possibility that targeted inclusion of this area into the treatment volume may improve survival [20, 22-26]. The largest of these studies assessed 173 subjects, and found that a higher ipsilateral SVZ dose correlated with better progression-free survival (PFS) and overall survival (OS) [25]. The next largest study involved 116 subjects, but found a benefit only within patients who underwent gross total resection (GTR) [26]. The SVZ is anatomically close to the hippocampal formation, and since irradiation of this region is potentially toxic [27,28], a clearer understanding of the potential benefit of targeting the SVZ is warranted. This study investigates whether SVZ dose is correlated with survival outcomes in a large cohort of GBM patients treated with radical long-course CRT and concomitant temozolomide.

\section{Materials And Methods}

\section{Patients}

The patients in this study received treatment at an institution that provides all radiotherapy services provincially. This study was approved by the institutional research ethics board. Between 2006 and 2012, all patients above age 18 with pathologically proven GBM treated at the institution with long-course CRT, who completed the full course of radiotherapy and at least $50 \%$ of the concurrent chemotherapy, were retrospectively reviewed $(n=370)$. This study period was chosen to allow sufficient follow-up time (minimum one year) to observe the primary endpoint of PFS. All had initial surgery with GTR, subtotal resection (STR), or biopsy, which was followed by adjuvant radiation (60 Gy in 30 fractions, intensity modulated radiotherapy (IMRT) or 3D-CRT) and at least 50\% of the prescribed concomitant temozolomide. Patients were excluded if they did not complete CRT, if full dosimetry data was unavailable, or if the intended final dose was less than $59.4 \mathrm{~Gy}$.

\section{Data collection}

Clinical data was extracted from an integrated electronic charting system. SVZs were retrospectively contoured on patients' planning CT scans, in accordance with operational definitions outlined in previous protocols $[23,24]$ as $5 \mathrm{~mm}$ along the lateral wall of the lateral ventricles for all treatment plans, with the use of co-registered magnetic resonance imaging (MRI) where available. This was done by two radiation therapists and one radiation oncology resident with training in SVZ contouring, and reviewed by a radiation oncologist specializing in central nervous system tumors. Dosimetry was analyzed with the analytical anisotropic algorithm on the Eclipse Planning System (Varian, version 11). Dose-volume histogram (DVH) data was collected for the ipsilateral, contralateral, and bilateral SVZ.

\section{Statistical analysis}

Statistical analysis was completed with R Version 3.2.5 (R Foundation, Vienna). The primary endpoints were PFS, defined as the time from histologic confirmation of GBM until radiologic evidence of disease progression and a change in patient management, and OS, until death. Kaplan-Meier (KM) curves of PFS and OS were constructed, comparing patients by dose to ipsilateral, contralateral, and bilateral SVZ. Known prognostic factors were also evaluated. KM curves were compared using the log-rank statistic, two-tailed, with $\mathrm{P} \leqslant 0.05$ denoting significance. For PFS, patients were censored at the time of last imaging showing stability if they had not progressed at the time of analysis. For OS, patients were censored at their last follow-up appointment or clinical investigation.

For univariate analysis of prognostic factors, patients were grouped by age ( $<50 \mathrm{vs.}>50)$, tumor location (frontal, temporal, parietal, occipital, cerebellar, butterfly, other), Karnofsky performance status (KPS, >70, $<70$ ), multifocality, resection (GTR, STR, biopsy), completion of concurrent chemotherapy, completion of adjuvant chemotherapy ( $>26,<26$ weeks), type of progression (local, distant, both), and time from diagnosis to CRT (<median, >median). The selected cut off for age has been used in similar studies of SVZ irradiation $[23,25]$. SVZ dosimetric data was evaluated for groups defined by cut-off points that included median dose, $40 \mathrm{~Gy}$, and $59.4 \mathrm{~Gy}$. The $40 \mathrm{~Gy}$ threshold was selected because SVZ doses in the range of 30-43 Gy have been suggested to be of prognostic significance [24, 26]. The 59.4 Gy threshold was evaluated due to the postulated radio-resistance of NSCs [25].

Multivariate Cox proportional hazards $(\mathrm{CPH})$ analysis was performed to identify independent predictors of PFS and OS. Variables included SVZ dose, age at diagnosis, biopsy only, Karnofsky performance status, multifocality, and adjuvant chemotherapy. All covariates, which were known prognostic factors for GBM patient outcome, were included regardless of their significance in the univariate analysis.

\section{Results}

Median follow-up time was 16.4 months for the cohort. Three-hundred sixty of the initial 370 patients were included in the analysis. Nine with incomplete dosimetric data, and one with an unconventional radiation prescription (neither $59.4 \mathrm{~Gy}$ nor $60 \mathrm{~Gy}$ ) were excluded. Baseline characteristics of the group are shown in Table 1. Dosimetric data including quartile doses are listed in Table 2. Median PFS for all patients was 8.9 months (95\% CI: 8.3-9.8 months), and OS was 16.5 months (95\% CI: 15.2-17.6 months). 


\section{Cureus}

\begin{tabular}{|c|c|c|}
\hline Characteristic & $N=36$ & \\
\hline \multicolumn{3}{|l|}{ Sex } \\
\hline Female & 118 & $(32.8 \%)$ \\
\hline Male & 242 & $(67.2 \%)$ \\
\hline \multicolumn{3}{|l|}{ Age (y) } \\
\hline$<50$ & 83 & $(23.1 \%)$ \\
\hline$>50$ & 277 & $(76.9 \%)$ \\
\hline \multicolumn{3}{|l|}{ Tumor location } \\
\hline Frontal & 113 & $(31.4 \%)$ \\
\hline Temporal & 119 & $(33.1 \%)$ \\
\hline Parietal & 84 & $(23.3 \%)$ \\
\hline Occipital & 22 & $(6.1 \%)$ \\
\hline Butterfly & 16 & $(4.4 \%)$ \\
\hline Other & 6 & $(1.7 \%)$ \\
\hline \multicolumn{3}{|l|}{ Karnofsky performance status } \\
\hline$>70$ & 280 & $(77.8 \%)$ \\
\hline$<70$ & 80 & $(22.2 \%)$ \\
\hline \multicolumn{3}{|l|}{ Multifocal } \\
\hline No & 301 & $(83.6 \%)$ \\
\hline Yes & 59 & $(16.4 \%)$ \\
\hline \multicolumn{3}{|l|}{ MRI size } \\
\hline$<$ Median & 180 & $(50 \%)$ \\
\hline > Median & 180 & $(50 \%)$ \\
\hline \multicolumn{3}{|l|}{ Resection } \\
\hline Gross total resection, GTR & 173 & $(48.1 \%)$ \\
\hline Subtotal resection, STR & 135 & $(37.5 \%)$ \\
\hline Biopsy & 52 & $(14.4 \%)$ \\
\hline \multicolumn{3}{|c|}{ Adjuvant chemotherapy completed } \\
\hline$>26$ Weeks & 176 & $(48.9 \%)$ \\
\hline$<26$ Weeks & 184 & $(51.1 \%)$ \\
\hline \multicolumn{3}{|c|}{ Concurrent chemotherapy completed } \\
\hline Yes & 339 & $(94.2 \%)$ \\
\hline No & 21 & $(5.8 \%)$ \\
\hline \multicolumn{3}{|l|}{ Progression type } \\
\hline Local & 257 & $(71.4 \%)$ \\
\hline Distant & 11 & $(3.1 \%)$ \\
\hline Both & 42 & $(11.7 \%)$ \\
\hline No evidence of progression & 50 & $(13.9 \%)$ \\
\hline
\end{tabular}




\section{Cureus}

3D-CRT

264

(73.3\%)

IMRT

Other

Total dose (cGy)

5940

Time from Dx to RT start (d)

Mean

MRI largest dimension (cm)

Mean

SD

TABLE 1: Patient demographics, disease, and treatment characteristics.

MRI: Magnetic resonance imaging; CRT: Chemoradiotherapy; IMRT: Intensity modulated radiotherapy; SD: Standard deviation.

\begin{tabular}{|c|c|c|c|}
\hline & Ipsilateral & Contralateral & Bilateral \\
\hline \multicolumn{4}{|c|}{ Mean SVZ dose (cGy) } \\
\hline Mean & 4778 & 2892 & 3790 \\
\hline Median & 4900 & 2806 & 3780 \\
\hline 1st Quartile & 4151 & 1952 & 3146 \\
\hline 3rd Quartile & 5606 & 3751 & 4416 \\
\hline \multicolumn{4}{|c|}{ Minimum SVZ dose (cGy) } \\
\hline Mean & 1835 & 908.9 & 845.1 \\
\hline Median & 1462 & 524.2 & 448 \\
\hline 1st Quartile & 345 & 179.6 & 173.1 \\
\hline 3rd Quartile & 2852 & 1426 & 1341 \\
\hline \multicolumn{4}{|c|}{ Maximum SVZ dose (cGy) } \\
\hline Mean & 3158 & 4846 & 6158 \\
\hline Median & 6136 & 5222 & 6145 \\
\hline 1st Quartile & 6070 & 3851 & 6073 \\
\hline 3rd Quartile & 6250 & 5974 & 6254 \\
\hline
\end{tabular}

TABLE 2: Radiation dosimetric data summary.

SVZ: Subventricular zone

On univariate analysis of all patients (Table 3), worse PFS was significantly associated with older age $(\mathrm{P}=$ $0.045)$, lower KPS ( $\mathrm{P}=0.049)$, multifocality $(\mathrm{P}<0.001)$, and failure to complete adjuvant chemotherapy $(\mathrm{P}<$ 0.001). Shorter OS was associated with lower KPS $(P=0.001)$, biopsy rather than resection $(P=0.003)$, 


\section{Cureus}

multifocality ( $\mathrm{P}=0.009)$, and failure to complete adjuvant chemotherapy $(\mathrm{P}<0.001)$. Dose was not significantly associated with either PFS (Figure 1) or OS, for any of the cut-off points assessed, for ipsilateral, contralateral, and bilateral SVZ, even when analysis was limited to patients who had GTR (Table 3).

\begin{tabular}{|c|c|c|c|c|c|}
\hline \multirow[b]{2}{*}{ Prognostic Factors } & & \multicolumn{2}{|l|}{ PFS } & \multicolumn{2}{|l|}{ os } \\
\hline & & Median (months) & P-value & Median (months) & P-value \\
\hline \multirow[t]{2}{*}{ Age } & $<50$ years & 10.4 & 0.045 & 17.8 & 0.234 \\
\hline & $>50$ years & 8.7 & & 16.0 & \\
\hline \multirow[t]{6}{*}{ Tumor location } & Frontal & 8.8 & 0.083 & 17.3 & 0.057 \\
\hline & Temporal & 9.9 & & 17.0 & \\
\hline & Parietal & 8.0 & & 14.5 & \\
\hline & Occipital & 9.6 & & 17.6 & \\
\hline & Butterfly & 11.7 & & 20.3 & \\
\hline & Other & 14.4 & & 13.6 & \\
\hline \multirow[t]{2}{*}{ Karnofsky score } & $>70$ & 9.7 & 0.049 & 17.1 & 0.001 \\
\hline & $<70$ & 7.2 & & 11.3 & \\
\hline \multirow[t]{2}{*}{ Multifocality } & No & 9.5 & $<0.001$ & 16.8 & 0.009 \\
\hline & Yes & 7.1 & & 13.7 & \\
\hline \multirow[t]{3}{*}{ Resection } & GTR & 9.5 & 0.245 & 17.2 & 0.003 \\
\hline & STR & 8.8 & & 17.0 & \\
\hline & Biopsy & 6.9 & & 10.7 & \\
\hline \multirow[t]{2}{*}{ Adjuvant chemotherapy } & $>26$ weeks & 13.6 & $<0.001$ & 23.7 & $<0.001$ \\
\hline & $<26$ weeks & 6.2 & & 10.6 & \\
\hline \multirow[t]{2}{*}{ Concurrent chemotherapy } & Completed & 9.0 & 0.535 & 16.5 & 0.615 \\
\hline & Incomplete & 8.3 & & 17.8 & \\
\hline \multirow[t]{3}{*}{ Progression type } & Local & 8.3 & 0.321 & 17.0 & 0.589 \\
\hline & Distant & 9.9 & & 15.0 & \\
\hline & Both & 9.8 & & 12.8 & \\
\hline \multirow{2}{*}{ Time from diagnosis to RT (median) } & $<39$ days & 9.0 & 0.864 & 16.5 & 0.664 \\
\hline & $>39$ days & 8.8 & & 16.6 & \\
\hline \multicolumn{6}{|l|}{ SVZ dosimetric data } \\
\hline \multirow[t]{6}{*}{ Ipsilateral dose } & < 49.0 Gy (median) & 8.7 & 0.251 & 16.9 & 0.618 \\
\hline & > 49.0 Gy (median) & 9 & & 15.7 & \\
\hline & $<40$ Gy & 9.6 & 0.594 & 17.4 & 0.259 \\
\hline & $>40$ Gy & 8.7 & & 15.6 & \\
\hline & $<59.4$ Gy & 8.8 & 0.240 & 16.5 & 0.194 \\
\hline & > 59.4 Gy & 10.1 & & 18.1 & \\
\hline \multirow[t]{3}{*}{ Contralateral dose } & $<28.1$ Gy (median) & 9.4 & 0.981 & 17 & 0.569 \\
\hline & > 28.1 Gy (median) & 8.4 & & 15.4 & \\
\hline & $<40$ Gy & 8.9 & 0.129 & 16.6 & 0.639 \\
\hline
\end{tabular}




\section{Cureus}

\begin{tabular}{|c|c|c|c|c|c|}
\hline & \multirow{2}{*}{$\begin{array}{l}>40 \mathrm{~Gy} \\
<59.4 \mathrm{~Gy}\end{array}$} & \multicolumn{2}{|l|}{9.7} & \multicolumn{2}{|l|}{16.5} \\
\hline & & 8.9 & 0.833 & 16.5 & 0.837 \\
\hline & $>59.4$ Gy & 11.5 & & 18.8 & \\
\hline \multirow[t]{6}{*}{ Bilateral dose } & $<40.8$ Gy (median) & 9 & 0.72 & 16.6 & 0.961 \\
\hline & $>40.8$ Gy (median) & 8.7 & & 16.5 & \\
\hline & $<40$ Gy & 8.8 & 0.277 & 16.4 & 0.645 \\
\hline & $>40$ Gy & 9 & & 16.9 & \\
\hline & $<59.4$ Gy & 8.9 & 0.862 & 16.5 & 0.312 \\
\hline & $>59.4$ Gy & 12.5 & & 16.9 & \\
\hline \multicolumn{6}{|c|}{ SVZ dosimetric data from the GTR group } \\
\hline \multirow[t]{6}{*}{ Ipsilateral dose } & $<46.4$ Gy (median) & 9.4 & 0.707 & 17.7 & 0.590 \\
\hline & > 46.4 Gy (median) & 9.8 & & 17 & \\
\hline & $<40$ Gy & 9.5 & 0.770 & 19.1 & 0.576 \\
\hline & $>40$ Gy & 9.7 & & 17.1 & \\
\hline & $<59.4$ Gy & 9.5 & 0.225 & 17.2 & 0.567 \\
\hline & $>59.4$ Gy & 10.1 & & 18.1 & \\
\hline \multirow[t]{6}{*}{ Contralateral dose } & $<23.4$ Gy (median) & 10.4 & 0.735 & 17.6 & 0.748 \\
\hline & > 23.4 Gy (median) & 9.4 & & 17 & \\
\hline & $<40$ Gy & 9.5 & 0.552 & 17.6 & 0.579 \\
\hline & $>40$ Gy & 9.7 & & 17 & \\
\hline & $<59.4$ Gy & & - & & - \\
\hline & > 59.4 Gy & & & & \\
\hline \multirow{6}{*}{ Bilateral dose } & $<34.9$ Gy (median) & 9.7 & 0.826 & 17.2 & 0.609 \\
\hline & > 34.9 Gy (median) & 9.1 & & 17.8 & \\
\hline & $<40$ Gy & 9.3 & 0.222 & 17.2 & 0.823 \\
\hline & $>40$ Gy & 10.8 & & 17.5 & \\
\hline & $<59.4$ Gy & & - & & - \\
\hline & > 59.4 Gy & & & & \\
\hline
\end{tabular}

TABLE 3: Univariate analysis of prognostic factors associated with PFS and OS.

PFS: Progression-free survival; OS: Overall survival; SVZ: Subventricular zone; GTR: Gross total resection; STR: Subtotal resection. 


\section{Cureus}
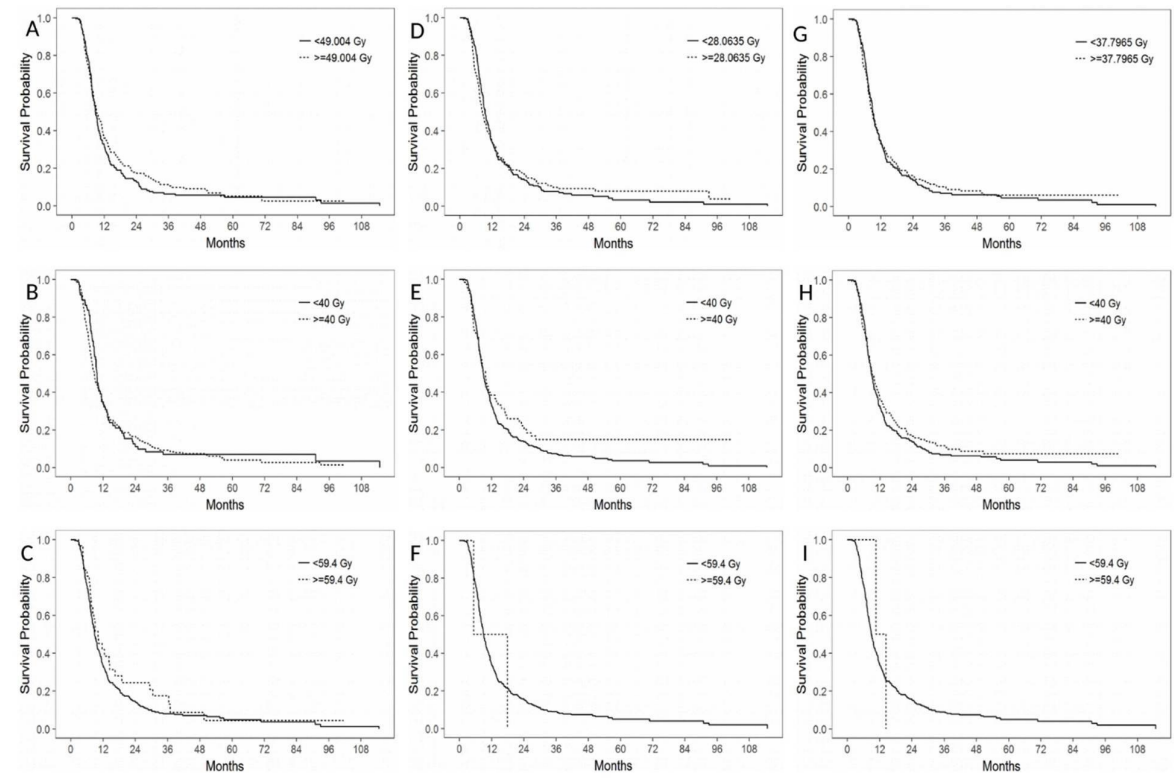

FIGURE 1: Progression-free survival according to dose to the ipsilateral

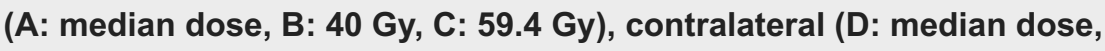
E: $40 \mathrm{~Gy}, \mathrm{~F}: 59.4 \mathrm{~Gy}$ ), and bilateral (G: median dose, H: $40 \mathrm{~Gy}$, I: $59.4 \mathrm{~Gy}$ ) subventricular zones.

For the multivariate analysis, stability of the model required the creation of different $\mathrm{CPH}$ models for each SVZ volume. Patients with multifocal tumors had significantly worse PFS, and patients with low KPS and minimal resection had significantly shorter OS (Table 4).

\begin{tabular}{|c|c|c|c|c|c|c|}
\hline & \multicolumn{3}{|c|}{ Progression-free Survival } & \multicolumn{3}{|c|}{ Overall Survival } \\
\hline & HR & $95 \% \mathrm{Cl}$ & P-value & HR & $95 \% \mathrm{Cl}$ & P-value \\
\hline \multicolumn{7}{|l|}{ Ipsilateral SVZ } \\
\hline Age $(>50$ years vs. $<50$ years $)$ & 1.24 & $0.95-1.63$ & 0.11 & 1.10 & $0.84-1.43$ & 0.50 \\
\hline Karnofsky score (< 70 vs. > 70) & 1.29 & $0.98-1.69$ & 0.07 & 1.51 & $1.16-1.96$ & $<0.01$ \\
\hline Resection (STR vs. GTR) & 1.05 & $0.81-1.36$ & 0.70 & 1.03 & $0.80-1.32$ & 0.83 \\
\hline Resection (biopsy vs. GTR) & 1.19 & $0.83-1.71$ & 0.33 & 1.62 & $1.15-2.28$ & $<0.01$ \\
\hline Multifocality (yes vs. no) & 1.51 & $1.11-2.04$ & $<0.01$ & 1.31 & $0.98-1.76$ & 0.08 \\
\hline Total dose (> 60 Gy vs. $<60$ Gy) & 0.85 & $0.59-1.22$ & 0.37 & 0.85 & $0.59-1.22$ & 0.37 \\
\hline Ipsilateral SVZ dose* & 1.00 & $0.99-1.01$ & 0.70 & 1.00 & 0.99-1.01 & 0.69 \\
\hline
\end{tabular}

\section{TABLE 4: Multivariate analysis.}

* Entered as a continuous variable.

SVZ: Subventricular zone; STR: Subtotal resection; GTR: Gross total resection.

\section{Discussion}

This study found that for patients treated with long-course CRT, dose to the SVZ was not associated with PFS or OS. Furthermore, no benefit to increasing SVZ dose was observed when analysis was restricted to patients with GTR, a subgroup identified by a previous study as uniquely benefitting from high SVZ dose [26]. 
Our results are contrary to prior studies that suggested higher dose to the SVZ improves outcome [20, 22-26]. However, these studies were small, and used variable inclusion criteria. Some failed to address known prognostic factors such as performance status [25] and adjuvant chemotherapy [25, 26]. Exclusion of multifocal tumors $[25,26]$ is also questionable, since multifocality is characteristic of stem-cell-derived tumors [14, 16] and often confers poor prognosis [29]. It is worth noting that our findings are applicable to patients receiving combined radiation and temozolomide; thus, conclusions about the effectiveness of SVZ irradiation without concurrent chemotherapy cannot be made. Our study population is similar to others in terms of the incidental dose received by the SVZ. The mean dose received by the ipsilateral SVZ in our cohort was $47.8 \mathrm{~Gy}$, which is very similar to Chen et al., at $49.2 \mathrm{~Gy}$, and Lee et al., at $48.7 \mathrm{~Gy}$. Due to the size of our study, our analysis had a larger group, $\mathrm{n}=32$, receiving a dose greater than $59.4 \mathrm{~Gy}$. This is important because it allows for a more robust comparison with those receiving a lower dose. Indeed, Lee et al., which is the second largest study looking at this issue, had only 21 individuals in their high dose group.

Discrepancy exists among studies of SVZ irradiation. Although some demonstrate benefit [20, 22-26], others have found no association between dose to the SVZ and outcome [18], and one conversely suggested high SVZ dose was associated with worse prognosis [17]. There is also disagreement within the positive studies as to which SVZ target volume may be associated with outcome (ipsilateral [22, 23, 25, 26], contralateral [22], or bilateral [24]).

The strengths of our study include its large size, with patients being treated at a single institution using a similar treatment protocol. Our study is limited by the retrospective nature of our data. We also employed very strict selection criteria, which has the potential to introduce selection bias. However, this was done to ensure our subjects would be comparable to those in prior studies of SVZ. Also, strict selection criteria were necessary to prevent further sources of bias. For example, subjects who did not complete radiotherapy were excluded; this was necessary, otherwise patients who deteriorated significantly during treatment would have inherently received a low SVZ dose, conceivably introducing further bias to the data. Chemotherapy compliance is potentially influenced by a number of factors (patient preference, toxicity, early tumor progression, etc.) which cannot be controlled in the retrospective setting, and although another important prognostic factor, it was not possible for this to be assessed. The most significant limitation of the present study is the lack of molecular marker data. It is well established that certain molecular features, such as IDH1 and MGMT status, can be prognostic and/or predictive of outcome [19]. Unfortunately, during the time period when study population was treated the institution did not routinely obtain molecular marker data on patients with GBM. It is certainly possible that SVZ dose could potentially have differential effects in the setting of different molecular phenotypes.

Targeting stem cell reservoirs may not be clinically beneficial, and can lead to larger volumes of brain tissue receiving radiation dose. This is important because current phase II trials are deliberately including the SVZ in their target volume [30]. The SVZ is anatomically close to the hippocampal formation, which is a structure important for memory and cognition that is being purposely avoided in studies using modern radiotherapy techniques $[27,28]$. In the future, it would be worthwhile for similar studies to include tumor genetics in their analysis.

\section{Conclusions}

The results of this study suggest that prognosis is unrelated to dose received by the SVZ. Indeed, prospective data are required to determine the value of SVZ irradiation in the treatment of GBM. However, trials deliberately including this region as a target volume should be done with caution.

\section{Additional Information \\ Disclosures}

Human subjects: Consent was obtained by all participants in this study. University of British Columbia Research Ethics Board issued approval n/a. This study was approved by our institutional research ethics board. Animal subjects: All authors have confirmed that this study did not involve animal subjects or tissue. Conflicts of interest: In compliance with the ICMJE uniform disclosure form, all authors declare the following: Payment/services info: All authors have declared that no financial support was received from any organization for the submitted work. Financial relationships: All authors have declared that they have no financial relationships at present or within the previous three years with any organizations that might have an interest in the submitted work. Other relationships: All authors have declared that there are no other relationships or activities that could appear to have influenced the submitted work.

\section{References}

1. Stupp R, Mason WP, van den Bent MJ, et al.: Radiotherapy plus concomitant and adjuvant temozolomide for glioblastoma. N Engl J Med. 2005, 352:987-996. 10.1056/NEJMoa043330

2. Weissman IL, Clarke MF, Morrison SJ, Reya T: Stem cells, cancer, and cancer stem cells . Nature. 2001, 414:105-111. 10.1038/35102167

3. Nicolis SK: Cancer stem cells and "stemness" genes in neuro-oncology . Neurobiol Dis. 2007, 25:217-229. 10.1016/j.nbd.2006.08.022 
4. Galli R, Binda E, Orfanelli U, et al.: Isolation and characterization of tumorigenic, stem-like neural precursors from human glioblastoma. Cancer Res. 2004, 64:7011-7021. 10.1158/0008-5472.CAN-04-1364

5. Yuan XP, Curtin J, Xiong YZ, et al.: Isolation of cancer stem cells from adult glioblastoma multiforme . Oncogene. 2004, 23:9392-9400. 10.1038/sj.onc.1208311

6. Bao S, Dewhirst MW, Hjelmeland AB, et al.: Glioma stem cells promote radioresistance by preferential activation of the DNA damage response. Nature. 2006, 444:756-760. 10.1038/nature05236

7. Abel TW, Clark C, Bierie B, Chytil A, Aakre M, Gorska A, Moses HL: GFAP-Cre-mediated activation of oncogenic K-ras results in expansion of the subventricular zone and infiltrating glioma. Mol Cancer Res. 2009, 7:645-653. 10.1158/1541-7786.MCR-08-0477

8. Ayuso-Sacido A, Moliterno JA, Kratovac S, et al.: Activated EGFR signaling increases proliferation, survival, and migration and blocks neuronal differentiation in post-natal neural stem cells. J Neurooncol. 2010, 97:323-337. 10.1007/s11060-009-0035-x

9. McKay R: Stem cells in the central nervous system. Science. 1997, 276:66-71. 10.1126/science.276.5309.66

10. Temple S: The development of neural stem cells . Nature. 2001, 414:112-117. 10.1038/35102174

11. Guerrero-Cázares H, Gonzalez-Perez O, Soriano-Navarro M, Zamora-Berridi G, García-Verdugo JM, Quinoñes-Hinojosa A: Cytoarchitecture of the lateral ganglionic eminence and rostral extension of the lateral ventricle in the human fetal brain. J Comp Neurol. 2011, 519:1165-1180. 10.1002/cne.22566

12. Quiñones-Hinojosa A, Sanai N, Soriano-Navarro M, et al.: Cellular composition and cytoarchitecture of the adult human subventricular zone: a niche of neural stem cells. J Comp Neurol. 2006, 494:415-434. 10.1002/cne.20798

13. Jafri NF, Clarke JL, Weinberg V, Barani IG, Cha S: Relationship of glioblastoma multiforme to the subventricular zone is associated with survival. Neuro-oncology. 2013, 15:91-96. 10.1093/neuonc/nos268

14. Lim DA, Cha S, Mayo MC, Chen MH, Keles E, VandenBerg S, Berger MS: Relationship of glioblastoma multiforme to neural stem cell regions predicts invasive and multifocal tumor phenotype. Neuro-oncology. 2007, 9:424-429. 10.1215/15228517-2007-023

15. Chaichana KL, McGirt MJ, Frazier J, Attenello F, Guerrero-Cazares H, Quinones-Hinojosa A: Relationship of glioblastoma multiforme to the lateral ventricles predicts survival following tumor resection. J Neurooncol. 2008, 89:219-224. 10.1007/s11060-008-9609-2

16. Smith AW, Mehta MP, Wernicke AG: Neural stem cells, the subventricular zone and radiotherapy: implications for treating glioblastoma. J Neurooncol. 2016, 128:207-216. 10.1007/s11060-016-2123-z

17. Elicin O, Inac E, Uzel EK, Karacam S, Uzel OE: Relationship between survival and increased radiation dose to subventricular zone in glioblastoma is controversial. J Neurooncol. 2014, 118:413-419. 10.1007/s11060-0141424-3

18. Chua M, Kusumawidjaja G, Gan P, Tan DH, Chua ET, Tham CK, Wong FY: Dose-escalated intensity modulated radiotherapy (IMRT) and increased radiation doses to subventricular zones (SVZ) in treatment outcomes of patients with glioblastoma multiforme (GBM). J Clin Oncol. 2014, 32:13031. 10.1200/jco.2014.32.15_suppl.e13031

19. Gupta T, Nair V, Jalali R: Stem cell niche irradiation in glioblastoma: providing a ray of hope? . CNS Oncol. 2014, 3:367. 10.2217/cns.14.39

20. Malik M, Akram KS, Joseph D, Valiyaveettil D, Ahmed SF: Prospective study of irradiation of potential stem cell niches in glioblastoma. Int J Radiat Oncol Biol Phys. 2015, 93:S111. 10.1016/j.ijrobp.2015.07.265

21. Nourallah B, Digpal R, Jena R, Watts C: Irradiating the subventricular zone in glioblastoma patients: is there a case for a clinical trial?. Clin Oncol. 2017, 29:26-33. 10.1016/j.clon.2016.09.005

22. Adeberg S, Harrabi SB, Bougatf N, et al.: Do increased doses to stem-cell niches during radiation therapy improve glioblastoma survival?. Stem Cells Int. 2016, 2016:10. 10.1155/2016/8793462

23. Gupta T, Nair V, Paul SN, Kannan S, Moiyadi A, Epari S, Jalali R: Can irradiation of potential cancer stemcell niche in the subventricular zone influence survival in patients with newly diagnosed glioblastoma?. J Neurooncol. 2012, 109:195-203. 10.1007/s11060-012-0887-3

24. Evers P, Lee PP, DeMarco J, Agazaryan N, Sayre JW, Selch M, Pajonk F: Irradiation of the potential cancer stem cell niches in the adult brain improves progression-free survival of patients with malignant glioma. BMC Cancer. 2010, 10:384. 10.1186/1471-2407-10-384

25. Lee P, Eppinga W, Lagerwaard F, et al.: Evaluation of high ipsilateral subventricular zone radiation therapy dose in glioblastoma: a pooled analysis. Int J Radiat Oncol Biol Phys. 2013, 86:609-615. 10.1016/j.ijrobp.2013.01.009

26. Chen LD, Guerrero-Cazares H, Ye XB, et al.: Increased subventricular zone radiation dose correlates with survival in glioblastoma patients after gross total resection. Int J Radiat Oncol Biol Phys. 2013, 86:616-622. 10.1016/j.ijrobp.2013.02.014

27. Barani IJ, Cuttino LW, Benedict SH, et al.: Neural stem cell-preserving external-beam radiotherapy of central nervous system malignancies. Int J Radiat Oncol Biol Phys. 2007, 68:978-985. 10.1016/j.ijrobp.2007.01.064

28. Gondi V, Tolakanahalli R, Mehta MP, et al.: Hippocampal-sparing whole-brain radiotherapy: a "how-to" technique using helical tomotherapy and linear accelerator-based intensity-modulated radiotherapy. Int J Radiat Oncol Biol Phys. 2010, 78:1244-1252. 10.1016/j.ijrobp.2010.01.039

29. Laws ER, Parney IF, Huang W, et al.: Survival following surgery and prognostic factors for recently diagnosed malignant glioma: data from the Glioma Outcomes Project. J Neurosurg. 2003, 99:467-473. 10.3171/jns.2003.99.3.0467

30. ClinicalTrials.gov. (2018). Accessed: November 20, 2018: https://clinicaltrials.gov/. 